\title{
Factors affecting post-traumatic stress disorder in children with orthopedic injury
}

\author{
Hüseyin Sina COSKUN ${ }^{1}$, Mirac Baris USTA ${ }^{2}$, Ferhat SAY ${ }^{1}$, Abdurrahman Murat YILDIRIM ${ }^{3}$ \\ ${ }^{1}$ ONDOKUZ MAYIS UNIVERSITY FACULTY OF MEDICINE-SAMSUN, DEPARTMENT OF ORTHOPEDICS AND TRAUMATOLOGY, TURKEY \\ ${ }^{2}$ ONDOKUZ MAYIS UNIVERSITY SCHOOL OF MEDICINE-SAMSUN, DEPARTMENT OF CHILD AND ADOLESCENT PSYCHIATRY, TURKEY \\ ${ }^{3}$ ZILE STATE HOSPITAL-TOKAT, TURKEY
}

\begin{abstract}
Introduction. Symptoms of psychological trauma are known to be seen at varying rates in children following extremity trauma. The treatment methods for paediatric fractures may affect the psychological symptoms experienced after trauma. The aim of this study was to determine post-traumatic stress disorder (PTSD) developing after fracture in paediatric patients and to investigate the fracture-related factors that could affect PTSD. Materials and Methods. The study included a total of 30 patients who presented at the Emergency Department and were diagnosed with an isolated, displaced fracture of any extremity. The patients were grouped according to the fracture localization and the treatment method. At the 1-month follow-up examination, the patients were evaluated by an orthopaedic surgeon and a child psychiatrist. A psychiatric interview was conducted and the PTSD Reaction Index (CPTSD-RI) for children and adolescents was applied. Results. The CPTSD-RI score at the end of one month was determined to be higher for children with a lower extremity fracture compared to those with an upper extremity fracture $(\mathrm{p}=0.151)$. No significant difference was determined between the general anaesthesia group and the sedation group $(\mathrm{p}=0.543)$. Conclusions. Psychological trauma symptoms generally start immediately after the traumatic event, may last for years if the treatment approach is not suitable and an increase in symptoms may be observed during follow-up. It can be recommended that attention is paid to children and adolescents with fractures, particularly of the lower extremity, in respect of PTSD symptoms.
\end{abstract}

\section{Introduction}

Although fractures involving the field of orthopaedics and traumatology can be seen at any age, childhood is a period when fractures are often seen. Fractures occurring in childhood do not generally require invasive interventions and are successfully treated with closed reduction methods and a plaster cast [1]. Post-Traumatic Stress Disorder (PTSD) is defined as the development in an individual of psychiatric symptoms including emotional, cognitive, behavioral and social disorders following the experience of a traumatic stress agent. Psychiatric symptoms are known to be seen at varying rates in children following fractures as a result of trauma [2]. The treatment methods for paediatric fractures may affect the psychological symptoms experienced after trauma. The aim of this study was to PTSD developing after fracture in paediatric patients and to investigate the fracture -related factors that could affect PTSD.

\section{Materials and Methods}

\section{Patient Group}

A total of 56 children presented at the Emergency Department of Ondokuz Mayis University Medical Faculty Hospital with a displaced fracture of any extremity and no additional system injury between March 2014 and March 2015 and were evaluated in respect of suitability for the study. Patients with pathological fractures, small and midsized bone fractures, non-displaced fractures, those who required further intervention because of reduction loss during follow-up, and patients with head trauma were excluded from the study. A total of 30 patients were included in the study. In the first examination, the 
localization of the fracture, the need for reduction or surgical intervention, the type of anaesthesia administered and the intervention made were recorded. At the follow-up examination 1 month after discharge, the patients were evaluated by an orthopedic surgeon and a child psychiatrist. In the orthopaedic examination, the maintenance of reduction and union were evaluated. In suitable patients, the plaster cast or brace was removed and physical therapy exercises were recommended for full range of joint movement. In the same follow-up examination, the Child/Adolescent PTSD Reaction Index (CPTSD-RI) was applied by a child psychiatrist in a structured psychiatric interview.

\section{Data collection tools: Child/Adolescent Post- Traumatic Stress Disorder Reaction Index (CPTSD-RI)}

The CPTSD-RI was developed by Pynoos et al to examine the PTSD symptoms in children and adolescents [3]. The semi-structured scale consists of 20 items to be answered with Likert-type responses to evaluate the reactions in children and adolescents to stress following various traumatic experiences [3, 4].

\section{Results}

A total of 30 patients were included in the study comprising 23 males and 7 females, with a mean age of 11.7 years (range, 8-18 years). The mean length of stay in hospital was 1.3 days.

The distribution of the fractures is shown in Table 1 . The patients were separated into groups of reduction under general anaesthesia (GA) [n=17] and reduction under sedation $(n=13)$. The procedures for all the femur and humerus fractures were applied under GA and for all the radius and tibia fractures under sedation.

When the fracture distribution was examined, all the 10 humerus fractures were extension type fractures. These were all applied with closed reduction under general anaesthesia then fixed with Kirschner wires (K wires). The 7 femur fractures were all located in the diaphysis and were treated with elastic nails in 3 cases and with plate and screw osteosynthesis in 4 cases. The 8 radius fractures were treated with closed reduction under sedation and depending on the swelling of the extremity, a plaster cast or a brace was applied. All the 5 tibia fractures were located in the diaphysis and were treated with closed reduction under sedation and a plaster cast.

In the orthopaedic evaluation after one month, no malunion, non-union or loss of reduction was seen in any patient. In the same session, the patients were evaluated in the Child Psychiatry Clinic. The comparisons of the CPTSD-RI scores according to fracture localization and anaesthesia type are shown in Tables 2 and 3 respectively.
The general anaesthesia patients were all hospitalized (mean length of stay, 1.4 days; range, 1-3 days) and the sedation patients were followed up as outpatients.

Table 1. Sociodemographic and clinical parameters of patients

\begin{tabular}{|c|c|c|c|}
\hline \multicolumn{4}{|l|}{ Study parameters } \\
\hline Mean age (years) & \multicolumn{3}{|c|}{$11.7 \pm 2.88$} \\
\hline \multirow[t]{2}{*}{ Gender $(\%)$} & \multicolumn{2}{|l|}{ Male } & $76.7 \%$ (n: 23$)$ \\
\hline & \multicolumn{2}{|l|}{ Female } & $23.3 \%$ (n: 7) \\
\hline \multirow[t]{4}{*}{ Fracture localization } & \multirow{2}{*}{$\begin{array}{l}\text { Upper } \\
\text { extremity }\end{array}$} & Humerus & $33.3 \%$ (n: 10$)$ \\
\hline & & Radius & $26.6 \%$ (n: 8$)$ \\
\hline & \multirow{2}{*}{$\begin{array}{l}\text { Lower } \\
\text { extremity }\end{array}$} & Femur & $23.3 \%$ (n: 7) \\
\hline & & Tibia & $16.6 \%(\mathrm{n}: 5)$ \\
\hline $\begin{array}{l}\text { Patients receiving } \\
\text { general anaesthesia }\end{array}$ & \multicolumn{3}{|c|}{$56.66 \%$ (n: 17$)$} \\
\hline $\begin{array}{l}\text { Patients receiving } \\
\text { sedation }\end{array}$ & \multicolumn{3}{|c|}{$43.34 \%$ (n: 13$)$} \\
\hline $\begin{array}{l}\text { CPTSD-RI score at } \\
\text { follow-up } 1 \text { month } \\
\text { after discharge }\end{array}$ & \multicolumn{3}{|l|}{$38.2 \pm 8.6$} \\
\hline
\end{tabular}

Table 2. Comparison of lower and upper extremity fracture group PTSD scores

\begin{tabular}{|l|c|c|c|c|}
\hline & $\begin{array}{c}\text { Isolated lower } \\
\text { extremity } \\
\text { fracture } \\
(\mathbf{n = 1 2})\end{array}$ & $\begin{array}{c}\text { Isolated upper } \\
\text { extremity } \\
\text { fracture } \\
(\mathbf{n = 1 8})\end{array}$ & $\mathbf{z}$ & $\mathbf{p}$ \\
\hline $\begin{array}{l}\text { CPTSD-RI } \\
\text { score }\end{array}$ & $37.54 \pm 13.36$ & $22.52 \pm 12.99$ & 1.931 & 0.151 \\
\hline
\end{tabular}

Note: Variables were analysed with the Mann-Whitney-U test

Table 3. Comparison of general anaesthesia and sedation group PTSD scores

\begin{tabular}{|l|c|c|c|c|}
\hline & $\begin{array}{c}\text { General } \\
\text { Anaesthesia } \\
(\mathbf{n = 1 7})\end{array}$ & $\begin{array}{c}\text { Sedation } \\
(\mathbf{n = 1 3})\end{array}$ & $\mathbf{z}$ & $\mathbf{p}$ \\
\hline $\begin{array}{l}\text { CPTSD-RI } \\
\text { score }\end{array}$ & $33.50 \pm 13.73$ & $29.54 \pm 13.57$ & 2.441 & 0.543 \\
\hline
\end{tabular}

Note: Variables were analyzed with the Mann-Whitney-U test

According to these results, the PTSD-I score at the end of one month was determined to be higher for children with a lower extremity fracture compared to those with an upper extremity fracture $(\mathrm{p}=0.151)$. No significant difference was determined between the general anaesthesia group and the sedation group $(\mathrm{p}=0.543)$. No significant difference was determined between the hospitalized group and the outpatient group $(\mathrm{p}=0.543)$.

\section{Discussions}

The requirement for treatment of fractures seen in childhood varies according to displacement of the fracture and the region. Supracondylar humerus fractures are the 
most frequently seen elbow fractures in children and constitute $3 \%$ of all paediatric fractures [4]. All the humerus fractures in this study were in the supracondylar region and were extension type fractures according to the Gartland classification [5]. After reduction of these fractures under general anaesthesia, fixation was made with K-wires. Postoperatively, a long-arm brace was applied for 4 weeks, then after removal, elbow joint movements were started.

Distal radius fractures are the most common orthopaedic injury in the paediatric population. The injuries generally occur as a result of a fall on to the open hand and axial loading or through the mechanism of direct trauma. Non-surgical treatment is the most common treatment option for patients with distal radius fractures, because there is significant potential for remodeling in the paediatric age group. If there is excessive angulation or displacement, percutaneous fixation or closed reduction maneuvers should be applied [6]. All the 8 radius fractures in this study were treated with closed reduction under sedation and a plaster cast. The patients were discharged on the same day with an outpatient polyclinic follow-up appointment. The plaster cast was removed after an average of 35 days and full joint movement exercises for the wrist were started.

Paediatric femoral shaft fractures constitute $<2 \%$ of all paediatric fractures. Nevertheless, these are the most common paediatric fractures requiring hospitalization and are the reason for prolonged hospital stay and immobilization [7]. The decision to treat a femoral shaft fracture with conservative or surgical methods is affected by many variables such as the age and weight of the patient, fracture type, concomitant injuries, polytrauma and the socio-economic status of the family [8]. Pelvipedal plaster cast, elastic nails, external fixator and submuscular plate and screw osteosynthesis are the preferred treatment methods. While pelvipedal plaster casting is the preferred treatment method in the first 6 years of life, there is ongoing debate concerning the most appropriate treatment after the age of 6 years.

The 7 femur fractures in the current study were treated with elastic nails in 3 cases and with plate and screw osteosynthesis in 4 cases. No significant difference has been found between these two methods in respect of complications and union rates [9]. However, elastic nail complications can be difficult sometimes, and in some cases may even require another surgical intervention [10]. The mean length of hospital stay because of femur shaft fracture was 1.7 days in this study. During follow-up no complications developed in any of these patients and all were mobilized with full weight-bearing at the end of mean 8 weeks.

One of the most common paediatric injuries seen by orthopaedic surgeons is tibia diaphysis fracture. The tibia is the third most common paediatric long bone fracture [11]. Treatment is personalized on the basis of patient age, concomitant injuries, fracture pattern, associated soft tissue and neurovascular damage and the surgeon's experience. Closed reduction and a plaster cast is usually the main method of treatment for diaphysis located paediatric tibia fractures [12]. All the 5 tibia fractures in the current study were closed fractures and were treated with closed reduction under sedation and plaster casting. The patients were mobilized with full weight-bearing at the end of mean 8 weeks.

As paediatric orthopaedic injuries are often seen in the Emergency Department, orthopaedic specialists usually organize the sedation and analgesia themselves for the injured child. While conscious sedation techniques are constantly developing, the therapeutic index between sufficient and excessive sedation is much narrower for children compared to adults, especially for painful procedures [13]. The appropriate alleviation of pain is important in the treatment of paediatric patients exposed to painful procedures. To achieve this, the pharmacological agent or combination of agents used must be easy to use, have a rapid onset, provide effective analgesia, there must be no airway or cardiopulmonary interaction and the time to recovery should be short $[14,15]$.

Ketamine hydrochloride is a pharmacological agent which creates a catatonic state resulting from a safe combination of amnesia and analgesia. Spontaneous respiration, muscle tone of the tongue and the cough and gag reflexes are protected [16]. The onset of the effect is rapid. A dose of $1 \mathrm{mg} / \mathrm{kg}$ has been reported to cause clinical effects at peak intensity and within 1 minute [17]. During awakening, nausea and vomiting may be observed, but these adverse effects can be prevented with the use of an anticholinergic providing secretion control [18]. In the current study, intravenous ketamine of $1 \mathrm{mg} / \mathrm{kg}$ was used for the patients applied with sedation. No side-effects were observed during awakening in any patient. However, in animal studies it has been reported that ketamine had the effect of increasing PTSD symptoms [19]. In the current study, the mean PTSD scores of the children administered with ketamine were determined to be lower than those of the children in the general anaesthesia group. Nevertheless, this property of ketamine should be kept in mind.

No direct relationship has been found between PTSD and the agent types used in general anaesthesia, but the existing mental state of patients observed with PTSD after general anaesthesia can be related with the psychosocial status [20]. Aceto et al recommended psychiatric followup of patients who develop PTSD symptoms following general anaesthesia.

PTSD can be seen to be associated with several factors. The primary of these are the characteristic traits of the child and the form of the trauma [21]. PTSD, especially in 
childhood, is not a well understood condition. When families have been interviewed, it has been observed that children tend to hide the memory of the trauma and symptoms. This affects the determination of PTSD in children [22, 23].

As PTSD causes a prolonged and abnormal catabolic state in the organism, this also affects wound healing. From a biological aspect, the diagnosis of PTSD in children demands importance [24, 25]. It can be considered that long-lasting PTSD could have an effect on fracture healing.

According to a study by Sanders et al, PTSD is extremely widespread in children and is observed in approximately one third of children experiencing orthopaedic trauma [26]. In the same study no relationship was found between PTSD symptoms and prolonged hospital stay. In the current study, 17 patients were hospitalized and the mean length of stay was determined as 1.4 days. The PTSD scores were determined to be high in the group with a lower extremity fracture who were treated under general anaesthesia and hospitalized. It is not clear in these patients whether the high PTSD scores were associated with the general anaesthesia, the hospitalization, or secondary to the temporary immobilization of a lower extremity fracture. In a study by Wallace et al, PTSD symptoms were observed in $33 \%$ of 76 paediatric patients. No significant difference was found between the frequency of PTSD seen following upper extremity fractures as a result of high energy trauma or from low energy trauma that did not require surgical intervention [27].

The most significant limitation of this study was that the follow-up period was limited to one month. Psychological trauma symptoms generally start immediately after the traumatic event, may last for years if the treatment approach is not suitable and an increase in symptoms may be observed during follow-up [28]. Traumatic fractures and PTSD are frequently seen in children and adolescents [29]. There is a need for further long-term follow-up studies to increase the knowledge of this subject. The number of the cases was another point of limitation. Finally, it's truly hard to distinguish if the disease is caused by the treatment process or the trauma itself. This need further investigation from both orthopedic surgeons and child and adolescent psychiatrists.

\section{Conclusions}

PTSD and other psychological trauma symptoms may be seen in children after traumatic fractures. According to the results of this study, these symptoms are seen more often in children with a lower extremity fracture than in children with an upper extremity fracture and therefore it can be recommended that attention must be paid to children and adolescents with fractures, particularly of the lower extremity, in respect of PTSD symptoms.
Conflict of Interest: All authors declare they have no conflict of interest.

Financial Support: No financial support has been provided for the study.

Ethical Approval and Informed Consent: Ethical approval was granted by the local ethical committee. Informed consent was obtained from the parents or legal guardians of the child.

Acknowledgment: Authors thank to Caroline J. Walker for language editing.

\section{References}

1. Lien J. Pediatric orthopedic injuries: evidence-based management in the emergency department. Pediatr Emerg Med Pract. 2017;14(9):1-28.

2. Daviss WB, Racusin R, Fleischer A, Mooney D, Ford JD, McHugo GJ. Acute stress disorder symptomatology during hospitalization for pediatric injury. J Am Acad Child Adolesc Psychiatry. 2000; 39(5): 569-575. doi:10.1097/00004583-200005000-00010.

3. Pynoos RS, Steinberg AM, Layne CM, Briggs EC, Ostrowski SA, Fairbank JA. DSM-V PTSD diagnostic criteria for children and adolescents: a developmental perspective and recommendations. J Trauma Stress. 2009;22(5):391-398. doi:10.1002/jts.20450.

4. Zorrilla S de Neira J, Prada-Cañizares A, MartiCiruelos R, Pretell-Mazzini J. Supracondylar humeral fractures in children: current concepts for management and prognosis. Int Orthop. 2015;39(11):2287-2296. doi:10.1007/s00264-015-2975-4.

5. GARTLAND JJ. Management of supracondylar fractures of the humerus in children. Surg Gynecol Obstet. 1959;109(2):145-154.

6. Dua K, Abzug JM, Sesko Bauer A, Cornwall R, Wyrick TO. Pediatric Distal Radius Fractures. Instr Course Lect. 2017;66:447-460.

7. John R, Sharma S, Raj GN, et al. Current Concepts in Paediatric Femoral Shaft Fractures. Open Orthop J. 2017; 11: 353-368. Published 2017 Apr 28. doi: 10.2174/1874325001711010353.

8. Kocher MS, Sink EL, Blasier RD, et al. Treatment of pediatric diaphyseal femur fractures. J Am Acad Orthop Surg. 2009; 17(11): 718-725. doi: 10.5435/00124635200911000-00006.

9. Wu QZ, Huang SM, Cai QX. Titanium elastic nail versus plate-screw fixation for the treatment of upper segment fractures of femoral shaft in children. Zhongguo Gu Shang. 2014;27(10):809-14.

10. Say F, Gürler D, Inkaya E, Yener K, Bülbül M. Which treatment option for paediatric femoral fractures in school-aged children: elastic nail or spica casting?. Eur J Orthop Surg Traumatol. 2014;24(4):593-598. doi:10.1007/s00590-013-1234-x. 
11. Shannak AO. Tibial fractures in children: follow-up study. J Pediatr Orthop. 1988;8(3):306-310. doi:10.1097/01241398-198805000-00010.

12. Mashru RP, Herman MJ, Pizzutillo PD. Tibial shaft fractures in children and adolescents. J Am Acad Orthop Surg. 2005; 13(5): 345-352. doi: 10.5435/00124635200509000-00008.

13. Cameron ML, Sponseller PD, Rossberg MI. Pediatric analgesia and sedation for the management of orthopedic conditions. Am J Orthop (Belle Mead NJ). 2000;29(9):665-672.

14. Yaster M, Deshpande JK. Management of pediatric pain with opioid analgesics. J Pediatr. 1988;113(3):421-429. doi:10.1016/s0022-3476(88)80622-x.

15. Terndrup TE. Pediatric pain control. Ann Emerg Med. 1996; 27(4): 466-470. doi: 10.1016/s01960644(96)70234-2.

16. Dachs RJ, Innes GM. Intravenous ketamine sedation of pediatric patients in the emergency department. Ann Emerg Med. 1997;29(1):146-150. doi:10.1016/s01960644(97)70321-4.

17. Corssen G, Hayward JR, Gunter JW, Groves EH. A new parenteral anesthesia for oral surgery. J Oral Surg. 1969;27(8):627-632.

18. Cravero JP, Blike GT. Review of pediatric sedation. Anesth Analg. 2004; 99(5): 1355-1364. doi: 10.1213/01.ANE.0000134810.60270.E8.

19. Saur L, Neves LT, Greggio S, et al. Ketamine promotes increased freezing behavior in rats with experimental PTSD without changing brain glucose metabolism or BDNF. Neurosci Lett. 2017; 658: 6-11. doi:10.1016/j.neulet.2017.08.026.

20. Aceto P, Perilli V, Lai C, et al. Update on posttraumatic stress syndrome after anesthesia. Eur Rev Med Pharmacol Sci. 2013;17(13):1730-1737.

21. Perry BD, Azad I. Posttraumatic stress disorders in children and adolescents. Curr Opin Pediatr. 1999;
11(4): 310-316. doi: 10.1097/00008480-19990800000008.

22. Almqvist K, Brandell-Forsberg M. Refugee children in Sweden: post-traumatic stress disorder in Iranian preschool children exposed to organized violence. Child Abuse Negl. 1997; 21(4): 351-366. doi: 10.1016/s0145-2134(96)00176-7.

23. Yule W. Posttraumatic stress disorder in the general population and in children. J Clin Psychiatry. 2001;62 Suppl 17:23-28.

24. van der Kolk BA, Saporta J. Biological response to psychic trauma. International handbook of traumatic stress syndromes: Springer; 1993. pp. 25-33.

25. Perry, BD Neurobiological Sequelae of Childhood Trauma: Post traumatic Stress Disorders in Children. In: Catecholamine Function in Post Traumatic Stress Disorder: Emerging Concepts (M Murburg, Ed.) American Psychiatric Press, Washington, DC, pp. 253276, 1994.

26. Sanders MB, Starr AJ, Frawley WH, McNulty MJ, Niacaris TR. Posttraumatic stress symptoms in children recovering from minor orthopaedic injury and treatment. J Orthop Trauma. 2005;19(9):623-628. doi:10.1097/01.bot.0000174709.95732.1b.

27. Wallace M, Puryear A, Cannada LK. An evaluation of posttraumatic stress disorder and parent stress in children with orthopaedic injuries. J Orthop Trauma. 2013;27(2):e38-e41. doi:10.1097/BOT.0b013e318250c837.

28. Stallard P, Velleman R, Langsford J, Baldwin S. Coping and psychological distress in children involved in road traffic accidents. $\mathrm{Br} J$ Clin Psychol. 2001;40(2):197-208. doi:10.1348/014466501163643.

29. Di Gallo A, Barton J, Parry-Jones WL. Road traffic accidents: early psychological consequences in children and adolescents. $\mathrm{Br} J$ Psychiatry. 1997;170:358-362. doi:10.1192/bjp.170.4.358. 